\title{
Biomarkers of Occupational Manganese Toxicity
}

\author{
Abbas Bahrami ${ }^{1}$, Ahmad Joneidi Jafari ${ }^{2 *}$, Hasan Asilian ${ }^{3}$, \\ Mohsen Taghizadeh ${ }^{4}$, Abalfadl Arjmand ${ }^{5}$ and Hosein Akbari ${ }^{6}$
}

\author{
${ }^{1}$ Phd student of Occupational Health, Faculty of Medical Sciences, \\ Occupational Health Department, Tarbiat Modares University, Tehran, Iran \\ ${ }^{2}$ Associated professor of Environmental Health, Faculty of Health, Environmental Health \\ Department, Iran Medical Sciences and Health services University, Tehran, Iran \\ ${ }^{3}$ Associated professor of Occupational Health, Faculty of medical sciences, \\ Occupational Health Department, Tarbiat Modares University, Tehran, Iran \\ ${ }^{4}$ Associated professor of Nutrition, Faculty of Medicine, Nutrition department, \\ Kashan Medical Sciences and Health Services University, Kashan, Iran \\ ${ }^{5}$ Associated professor of Physiology, Faculty of Medicine, Physiology department, \\ Kashan Medical Sciences and Health Services University, Kashan, Iran \\ ${ }^{6}$ Assistant Professor of public Health, Faculty of Health, public Health Department, \\ Kashan Medical Sciences and Health Services University, Kashan, Iran.
}

DOI: http://dx.doi.org/10.13005/bbra/1885

(Received: 01 June 2015; accepted: 20 August 2015)

\begin{abstract}
Manganese (Mn) is an essential trace element that is required for maintaining normal function in the human body. However, excessive exposure to Mn has been associated with Parkinson-like symptoms of a disease called manganism. Mn exposure is occurred in different occupational settings such as mining, steel and alloy production, welding and dry cell battery manufacturing. Biological monitoring of chemical exposure in the workplace has become increasingly important in the assessment of health risk as an integrating part of the overall strategy in the occupational health and safety. This activity requires accurate sampling and analysis with correct interpretation of results. Biological monitoring is an important tool in the prevention of occupational diseases related to those exposed to chemicals such as manganese on a regular basis. Particularly, when there may be multi-route exposures (inhalation, skin and ingestion) or abnormal exposures. No reliable biomarker has been established to evaluate the effects of Mn exposure. A complete scientific understanding of the mechanism of Mn induced toxicity remains undiscovered. Over the past decade, extensive researches using animal models and human communities have led to several potential indicators of Mn exposure and biological effects. The present study aimed to identify reliable biomarkers of Mn exposure and toxicity. Using keywords such as biomarkers and manganese toxicity in the available databases, the relevant papers published from 1990 to 2014 were found and those having our criteria were selected. The results were obtained by analyzing the collected data. The biomarkers of Mn exposure such as Mn concentration in biological fluids (blood, urine and saliva) and some parts of body (hair and nail) were investigated. Mn of blood and urine are not good markers to evaluate the exposure. Although Mn in blood is different in group comparison of those having active exposure than those not exposed to it, it is not valid for the individuals. Biomarkers related to Mn poisoning effects including variation in Mn to Iron Ratio (MIR), variation in iron and regulatory proteins of iron, serum prolactin, auric acid (ROS) Reactive Oxygen Species, and MRI were investigated. Regarding criteria for a good biomarker, each investigated biomarker had a number of advantages and disadvantages. Therefore, further researches are required to introduce an appropriate biomarker for Mn exposure and effects to prevent manganism in workers exposed to Mn. Mn-exposed biological indicators such as Mn concentration in biological fluids (blood, urine and saliva) and some parts of body (hair, nail and bone) are studied. Mn of blood and urine are not good indicators to evaluate the exposure. However, Mn in blood for group comparison of current exposure is good but not for the discrimination of an individual. Biological indicators related to effects are Mn to Iron Ratio (MIR), variation in iron and regulatory proteins of Iron, serum prolactin, auric acid, (ROS) Reactive Oxygen Species, and MRI. Concerning the criteria for a good indicator, every mentioned indicator has a number of advantages and disadvantages. Thus, it is indispensable to conduct additional researches to introduce an appropriate indicator in order to prevent manganism in workers.
\end{abstract}

Key words: Biomarkers, Manganese, Occupational Exposure, Manganism

\footnotetext{
* To whom all correspondence should be addressed.

Te.l: 0936725435 ;

E-mail: Jonidi.a@IUMS.ac.ir
} 
To evaluate the risk of occupational exposure to chemical agents, quantifying the exposure levels is required to determine the risk levels of the workers. A toxic chemical agent can be determined by measuring its concentration in workplace ambient air and comparing the results with the allowed threshold limits recommended by organizations such as ACGIH and OSHA. Since the amounts of the allowed threshold limit are considered safe values, it can only determine the potential toxicity of a chemical. Due to different personal characteristics and sensitivities of workers, knowledge about exposure levels alone is not sufficient for risk assessment. Therefore, using biomarkers as an adjunctive tool for the exposure limits is necessary ${ }^{1,2}$.

Biological indicators reflect the values of the chemical or its metabolites in tissues and biological fluids are measured.

For example, blood lead levels as a biological indicator is able to determine the boundary between safe and unsafe in confronting with the metal.

Although Manganese is an essential element in an indefinite status and is required for human exposure to excessive amounts can lead to diseases like Parkinson's disease, which is known as Manganism¹.

Manganese is an essential trace element in the diet of all animals

It is essential for many enzymatic reactions such as the synthesis of amino acids, protein and carbohydrates. [3]. It is found in many rocks and soils of the earth, and is vital to ensure the health and proper functioning of various body systems including the skeletal system, immune, nervous and reproduction ${ }^{4}$.

The major sources of dietary manganese are whole grains, fish, vegetables, nuts and beverages such as tea and coffee $^{5}$.

The determined the recommended amount of manganese in the diet is difficult, but America National Research Council has determined 2-5 mg per day for adults as the safe enough magnesium in the diet ${ }^{6}$.

According to FDA (Food and Drug Administration) and NAS (National Academy of Sciences) the daily withdrawal amount of manganese is $2.3 \mathrm{mg}$ for men and $1.8 \mathrm{mg}$ for women $^{7}$.
The average manganese air approximately is 0.02 micro-grams per cubic meter ${ }^{8}$.

In the U.S. the amount of manganese in the water is less than 0.05 million $^{9}$.

Although manganese deficiency in the diet is rare, it can cause the effects. Manganese deficiency in animals is associated with growth disorders, reproductive system, testicular atrophy in male animals, skeletal disorders and imbalance in carbohydrate and fat metabolism ${ }^{10}$.

A few cases of manganese deficiency in humans has been reported that its symptoms are dermatitis, slow growth of hair and nails, reduction of serum cholesterol levels and protein values required for blood clotting ${ }^{7,11,12}$.

The threshold limit of manganese is 0.2 $\mathrm{mg} / \mathrm{m}^{3} \mathrm{ACGIH}$ based on the latest book concerning threshold limit. Occupational exposure to high levels of manganese is mainly occurred in miners and welders. Long-term exposure to manganese can cause Parkinson-like disease that is called "Manganism"13. During recent years using biomarkers in different fields such as medicine, industry, and environmental sciences has been dramatically expanded $\mathrm{d}^{14-17}$.

The use of biomarkers in risk assessment has grown considerably in the past decade.

These markers are visible tool show that the person will become sick.

This particular markers in the evaluation of chronic disease whose symptoms will appear after a long time after exposure, are important because at the time, the disease is not reversible ${ }^{18}$. The complexity of the nervous system does not allow a biomarker sensitive, specific and reliable to be determined for neurotoxicity easily and fast.

However, provided biomarkers are promising ${ }^{14}$. Determining a valid and reliable biomarker to identify manganese poisoning easily at an early stage before symptoms appear is necessary.

The aim of this study was to investigate the introduction of biomarkers in human and animal studies related to exposure to manganese.

\section{MATERIALSANDMETHODS}

Using the keywords Biomarkers and Manganese, the relevant articles were searched in available databases and then the article, having 
the intended criteria, were selected.

Human studies conducted in the workplace, exposure to manganese, published papers from 1990 to 2014, and the determination of the amount of manganese biological fluids were among the conditions.

In addition, it was attempted to select articles that were related to people with more experience and higher quality. Results were extracted by analyzing the collected data.

\section{RESULTS}

\section{Manganese concentrations in body fluids as a biomarker of exposure}

After inhalation exposure to manganese, this element is introduced into the bloodstream. Therefore, most studies on biomarkers primarily consider blood manganese.

Studies on rodents indicate that manganese concentration in the blood significantly increases after injection, oral or inhaled exposure ${ }^{2,19-22}$.

However, experimental studies on laboratory animals have reported similar results, but studies in human societies have reported conflicting results ${ }^{23-24}$. The use of manganese concentrations in the blood has been studied as a biomarker of exposure to manganese among welders, metal workers, miners and workers making dry batteries ${ }^{25-36}$.

In general, these studies revealed that the concentration of blood manganese as an acceptable index is also reflected in the comparison group in the face of active and current exposure and it is the most common indicator used to compare groups and the control group.

The low sensitivity of the use of blood manganese as biomarker is because half-life of manganese blood is shorter than its half-life in the tissue.

Toxicokinetic studies indicated that halflife of manganese in Rat's blood plasma is less than 2 hrs, while the level in its brain is over 50 $\mathrm{hrs}^{33}$. The intracellular distribution of manganese ions underlies the mismatch between blood manganese and the actual concentration of manganese in the target tissue or organ, especially the brain ${ }^{11}$. Manganese Urine (MnU) is considered as a non-invasive method. Since manganese is primarily excreted through feces and urine manganese and Manganese is a small part of the body many of the changes have been observed between exposure and urine manganese and should not be used as a biomarker. In one study conducted by Hoet et al. (2012) a urine manganese concentration of $65 \%$ of welders was below the detection limit (LOQ) $)^{34}$. The results of studies on the amount of manganese found in the urine of workers exposed to manganese are presented in Table 2-1 26, 29,35-42.

The concentration of saliva manganese has been studied as a biological indicator of exposure in a number of studies ${ }^{42-44}$. In the study conducted by Dixing Wang et al. (2008) the use of saliva manganese in welders is studied as a reliable biomarker.

In this study, the Air Mn values for the control group, low exposure and high exposure groups were $0.01,0.24$ and $2.21 \mathrm{mg}$ per cubic meter of air, respectively.

Manganese saliva was measured using ICP that manganese in welding saliva was significantly higher than the control group $(p<0.01)$ as well as changes in the saliva of the workers was related to workers' exposure to manganese ${ }^{42}$.

Fernando Gill et al. (2011) determined the concentration in the saliva of 178 patients who had occupational exposure to heavy metals.

The results indicated that those who had more experience had higher concentration in saliva and they concluded that saliva can be used as a biomarker of manganese excess or replace biological blood used in monitoring ${ }^{43}$. Zhou Yz et al. (2010) determined a biomarker for job exposure in order to identify air manganese samples in exposed individuals. Then manganese concentrations in saliva, plus a number of other fluids and tissues were determined.

Results showed that the manganese concentration in saliva can be used as a biomarker in patients exposed to manganese ${ }^{44}$.

Mn hair concentration is considered due to ease of access and as other non-invasive method. Several studies have emphasized that with increasing experience, hair manganese concentrations increases as a biomarker ${ }^{43-45}$.

Bader et al. (1999) found that compared with the exposed group controls, manganese of the exposed armpit hair was 3 times than that of 
control group ${ }^{45}$

It is likely that this difference is caused by secondary pollution.

Nails and fecal Mn has been studied as a biomarker, but a lot of changes are shown in the results.

For example, the range between 0.07 to 15.9 micrograms manganese per gram of feces and fecal 0.02 to 14.7 micrograms per gram of nails was observed among exposed welders. Unfortunately, this study lacked control group ${ }^{46}$.

The properties of manganese allow noninvasive method Magnetic Resonance Imaging
(MRI) to determine the amount of manganese. For this purpose, the Pallidus Index (PI) has been used.

The index is the ratio of signal intensity in the subcortical white matter in the anterior base of the axial $\mathrm{T} 1$ is at 100 dead $^{11}$.

In one study, by Yueming Jiang et al. (2007) used MRI as a biological indicator of manganese in metal smelting workers and drawn the conclusion that the mean PI scores among workers with low and high levels were $4.7 \%(\mathrm{P}<0 / 05)$ and $1.16 \%$ ( $\mathrm{P}$ $<0 / 01)$, respectively that manganese exposure increased compared with the control group ${ }^{47}$.

Table 1. Results of studies on blood manganese as a biomarker

\begin{tabular}{|c|c|c|c|c|c|}
\hline Row & Author(s) & $\begin{array}{l}\text { The number } \\
\text { of control } \\
\text { subjects }\end{array}$ & $\begin{array}{l}\text { Studied } \\
\text { occupation }\end{array}$ & $\begin{array}{l}\text { Blood manganese } \\
\text { concentration of } \\
\text { control } \\
\text { subjects }(\mu \mathrm{g} / \mathrm{l})\end{array}$ & $\begin{array}{l}\text { Air manganese } \\
\text { concentration } \\
\left(\mathrm{mg} / \mathrm{m}^{3}\right)\end{array}$ \\
\hline \multirow[t]{2}{*}{1} & \multirow{2}{*}{$\begin{array}{l}\text { Luncchini } \\
\text { et al. (1997) }\end{array}$} & 61 & Alloy & 9.8 & \multirow[t]{2}{*}{0.3} \\
\hline & & 87 & $\begin{array}{l}\text { production, ore } \\
\text { crushing, melting }\end{array}$ & 6.8 & \\
\hline \multirow[t]{2}{*}{2} & \multirow{2}{*}{$\begin{array}{l}\text { Bast Pettersen } \\
\text { et al. (2004) }\end{array}$} & 100 & Alloy & 10.4 & \multirow[t]{2}{*}{0.3} \\
\hline & & 100 & $\begin{array}{l}\text { production, ore } \\
\text { smelting, } \\
\text { furnace }\end{array}$ & 9.2 & \\
\hline \multirow[t]{2}{*}{3} & \multirow[t]{2}{*}{ Blond et al.(2007) } & 92 & Metallurgy & 10 & \multirow[t]{2}{*}{-} \\
\hline & & 19 & & & \\
\hline \multirow[t]{2}{*}{4} & \multirow{2}{*}{$\begin{array}{l}\text { Chia et al. } \\
\text { (1993) }\end{array}$} & 17 & Mining & 25.3 & \multirow[t]{2}{*}{1.59} \\
\hline & & 17 & & 23.3 & \\
\hline \multirow[t]{2}{*}{5} & \multirow{2}{*}{$\begin{array}{l}\text { Elingsen et al. } \\
(2008)\end{array}$} & 96 & Production of & 8.6 & \multirow[t]{2}{*}{0.12} \\
\hline & & 96 & $\begin{array}{l}\text { heavy } \\
\text { machinery, } \\
\text { shipbuilding and } \\
\text { welding }\end{array}$ & 6.9 & \\
\hline \multirow[t]{2}{*}{6} & \multirow{2}{*}{$\begin{array}{l}\text { Luncchini et } \\
\text { al. (1999) }\end{array}$} & 35 & Mining & 9.7 & \multirow[t]{2}{*}{0.19} \\
\hline & & 27 & & 6.8 & \\
\hline \multirow[t]{2}{*}{7} & \multirow{2}{*}{$\begin{array}{l}\text { Mergler et al. } \\
\text { (1994) }\end{array}$} & 73 & Mining & 11.3 & \multirow[t]{2}{*}{0.23} \\
\hline & & 73 & & 7.2 & \\
\hline \multirow[t]{2}{*}{8} & \multirow{2}{*}{$\begin{array}{l}\text { Myers et al. } \\
\text { (2003) }\end{array}$} & 101 & Metallurgy & 13.6 & \multirow[t]{2}{*}{0.77} \\
\hline & & 67 & & 6.4 & \\
\hline \multirow[t]{2}{*}{9} & \multirow{2}{*}{$\begin{array}{l}\text { Roles et al. } \\
\text { (1992) }\end{array}$} & 92 & Dry cell battery & 8.1 & \multirow[t]{2}{*}{0.95} \\
\hline & & 101 & manufacturing & 6.8 & \\
\hline \multirow[t]{2}{*}{10} & \multirow{2}{*}{$\begin{array}{l}\text { Roles et al. } \\
\text { (1987) }\end{array}$} & 92 & Production of & 13.6 & \multirow[t]{2}{*}{0.94} \\
\hline & & 101 & $\begin{array}{l}\text { manganese } \\
\text { oxides and salts }\end{array}$ & 5.7 & \\
\hline \multirow[t]{2}{*}{11} & \multirow{2}{*}{$\begin{array}{l}\text { Sjogren et al. } \\
\text { (1996) }\end{array}$} & 12 & Rail building, & 8.5 & - \\
\hline & & 39 & welding & 7 & \\
\hline 12 & Wang et al. & 82 & Welding, & 20.5 & 0.25 \\
\hline & (2006) & 51 & $\begin{array}{l}\text { automobile } \\
\text { building }\end{array}$ & 12.5 & \\
\hline 13 & Yuan et al. & 56 & Machining, & 48.4 & 0.14 \\
\hline & 2006 & 34 & welding & 19.2 & \\
\hline
\end{tabular}


MRI features of this technique potentially are a valuable method to detect exposure to manganese.

The increase of Manganese is in the bilateral and symmetric forms.

The signals among workers who have been exposed but do not show symptoms can be detected.

Signal strength with $\mathrm{P}$ indicator and Manganese cells of blood have significant relation with each other.
Not only high signal intensity in the basal area but nigra striatum has been observed in the workers with Manganism.

Abnormally high exposure to manganese may disappear after 6 months ${ }^{11}$.

Manganese toxicity biomarkers or biological indicators of effectiveness:

Biochemical, physiological changes, behavioral or other in an organism occurs after exposure to manganese that can determine the potential effects

Table 2. Results of a number of studies on urine manganese as a biomarker

\begin{tabular}{|c|c|c|c|c|c|}
\hline Row & Author(s) & $\begin{array}{l}\text { The number } \\
\text { of control } \\
\text { subjects }\end{array}$ & $\begin{array}{l}\text { Studied } \\
\text { occupation }\end{array}$ & $\begin{array}{l}\text { Manganese } \\
\text { concentrations in } \\
\text { urine of control } \\
\text { subjects }(\mu \mathrm{g} / \mathrm{l})\end{array}$ & $\begin{array}{l}\text { Air manganese } \\
\text { concentration } \\
(\mathrm{Mg} / \mathrm{m} 3)\end{array}$ \\
\hline 1 & $\begin{array}{l}\text { Roels et al. } \\
\text { (1992) }\end{array}$ & $\begin{array}{l}92 \\
101\end{array}$ & $\begin{array}{l}\text { Battery } \\
\text { manufacturing }\end{array}$ & $\begin{array}{l}0.84 \\
0.09 \\
\text { (per gram } \\
\text { of creatinine) }\end{array}$ & 0.948 \\
\hline 2 & $\begin{array}{l}\text { Lucchini et al. } \\
\text { (1999) }\end{array}$ & $\begin{array}{l}61 \\
87\end{array}$ & $\begin{array}{l}\text { Alloy } \\
\text { production }\end{array}$ & $\begin{array}{l}1.53 \\
0.4 \\
\text { (per gram } \\
\text { of creatinine) }\end{array}$ & 0.0542 \\
\hline 3 & Laohaudomchok et al. (2011) & $27-$ & Welding & $1.5(\mathrm{ng} / \mathrm{ml})$ & 0.0128 \\
\hline 4 & Lucchini et al. (1995) & $58-$ & Alloy production & 2.27 & 0.671 \\
\hline 5 & Järvisalo et al. (1992) & 58 & Welding & 0.31 & 0.26 \\
\hline 6 & Hua and Huang (1991) & - & Alloy production & 132 & $2>$ \\
\hline 7 & Teresa et al. (1997) & - & Alloy production & $\begin{array}{l}0.6 \text { (per gram } \\
\text { of creatinine) }\end{array}$ & 0.43 \\
\hline 8 & Hassani et al. (2012) & $\begin{array}{l}118 \\
37\end{array}$ & Welding & 7.58- 0.77 & 0.3 \\
\hline 9 & $\begin{array}{l}\text { Apostoli et al. } \\
(2000)\end{array}$ & $\begin{array}{l}94 \\
87\end{array}$ & Alloy production & $\begin{array}{l}3.8 \\
0.7\end{array}$ & 0.15 \\
\hline
\end{tabular}

of poisoning or disease. Therefore, on the basis of hypothetical mechanisms of Mn neurotoxicity is presented.

The changes in the iron and iron regulatory protein

Manganese and iron compete for places of the same link. Data from human studies indicate that iron levels in individuals exposed to $\mathrm{Mn}$ are reduced and the results are shown in the experimental studies on laboratory animals. Cowan et al. (2009) in a study of 95 people exposed to manganese in a metal smelter (high exposure) and 122 administrative employees of the same factory (face down) and 106 subjects in a control group not exposed to concentrations determined iron and manganese in saliva, plasma, erythrocytes, urine and hair With the increase of manganese concentrations in biological materials, metal concentration in plasma and erythrocyte significantly reduced in exposed workers compared to the control group. For this reason, the authors suggest that manganese to iron ratio can be used as a biomarker to distinguish exposed and unexposed ones ${ }^{48}$.

\section{The biomarkers of oxidative stress}

Oxidative stress occurs when free radicals are produced in large quantities that their production mechanism is reviving oxygen. One of 
the potential sources of oxidative stress is excessive exposure to manganese.

In mammals, manganese tends to accumulate in areas that are rich in dopamine in the ganglion Bashdbvyzhh basis ${ }^{49}$. Another manganese mechanism in the production of oxygen species (ROS) is involved through the impact on the molecules within the cell.

Several enzymes that produce ROS such as Superoxide Dismutase (SOD), Malondialdehyde (MAD), Glutamine Synthetase (GS), Metallothionein (MT), or Glutathione (GSH) are known as the markers of systemic oxidative stress $^{11}$. A number of researchers have used these markers as biomarkers of exposure to manganese.

In one study, Chtourou et al. (2014) investigated the protective role of silymarine (as an antioxidant) in the prevention of oxidative stress resulting from exposure to manganese in rats. They found that it plays a significant role in the development of oxidative stress caused by exposure to manganese ${ }^{49}$.

Furthermore, Prolactin been studied as a biomarker effects of manganese toxicity ${ }^{50,51}$. In one study, Sergio Montes et al. (2008) describe the relationship between blood manganese and prolactin as a biomarker in people living near mining areas in Mexico who were exposed to manganese. Multiple regression analysis indicated that manganese levels in blood is an important factor in the value of serum prolactin ${ }^{51}$.

In the study conducted by Kim et al. (2007) the effect of occupational exposure to manganese on prolactin in 251 welding jobs and 100 administrative employees who were matched for age and sex, as the control group was analyzed. The results of study indicated that with the increase of exposure to manganese prolactin levels increased $^{50}$.

Moreover, a biomarker of uric acid in urine is examined. In a study conducted by SUN XiaoMing et al. (2011) on 65 welders, the results showed that the amount of uric acid in urine of people exposed to manganese was significantly lower than that of control group ${ }^{52}$.

Considering approximately $40 \%$ of manganese accumulating in the bone ${ }^{53}$. A method is also provided with X-ray spectroscopy that small amounts of various metals such as lead and manganese can be measured and a number of studies have been conducted on Manganese. Pejoviæ-Miliæ et al. (2009) using neutron activation analysis measured the bone manganese of 30 welders and 10 persons as the control group. The results indicated a significant difference between the control group exposed to manganese and manganese bone $(\mathrm{P}<0 / 05)$. It seems that the amount of manganese can be used as a marker of bone $^{54]}$ In addition to the work and experimental studies on laboratory animals, a number of studies are relevant to people exposed to manganese in the environment ${ }^{51,55-62}$.

In most of these studies, examined people's behavior is to be mentioned in a separate article.

\section{DISCUSSION}

It is important to emphasize manganese poisoning is usually progressive and irreversible because of the permanent damage to the neural structure.

The search for a reliable marker or a biomarker that can indicate the risk of manganese toxicity is essential in the studies of occupational health.

Scientific research is necessary to achieve such a biomarker. Numerous studies have been carried out on biomarkers related to manganese and manganese in biological fluids and tissues in the investigation so as to determine whether they can be used as a biomarker of the contract.

For a reliable indicator, it is desirable that the exposure of dose-response relationship is correlated.

Since the measurement of external exposure dose is not usually available in workplaces, manganese exposure is unknown.

Measuring blood and urine manganese problems and their relationship with external exposure are unknown.

$\mathrm{Mn}$ in blood or urine as a biomarker studies are presented.

Manganese has a short half-life in blood and the amount of time sampling and a short time before sampling are measured.

Regarding Manganese in urine, it should be noted that it is exerted mainly through the feces and only a small amount is excreted through the urine. 
In sum, based on the articles, blood and urine manganese often can be used to show the difference between exposed and unexposed groups, but due to the change of the results, these indicators cannot be introduced as a suitable biomarker.

The ratio of Manganese to iron is suitable for biological monitoring. From the perspective of assessing exposure to the ratio of manganese to iron in erythrocytes (eMIR) compared to the ratio of manganese to plasma iron (pMIR) has a higher value because it shows higher correlation with the amount of air manganese ${ }^{48}$.

It seems that eMIR is more dependent on exposure and pMIR is related to the effects of manganese.

Manganese and other metals measured in saliva samples have several advantages including saliva secreted by the salivary glands and contain components of the extracellular body. Metal ions such as manganese are not essential only through the influence of non-active but also take active transport

Thus, theoretically, different chemical properties of saliva, serum and saliva make it appropriate to examine manganese.

Other saliva samples can be easily prepared and maintained and a non-invasive procedure is a better and more comfortable and can be stored and sent to the laboratory for analysis.

One of the limitations associated with the use of saliva is the intervention factors of diseases such as ulcers and dental infection.

However, in a number of studies, it is suggested that manganese saliva can be used as a biomarker $^{42,43}$.

Indicators weighed $\mathrm{T} 1$ and $\mathrm{pI}$ in MRI still continue to be used as a non-invasive and sensitive biomarker for assessing exposure to manganese in workers ${ }^{47}$.

The usefulness of MRI in studies also is approved $^{11,63-67}$.

Only in one article of uric acid, urine is investiagted as a biomarker of manganes $\mathrm{e}^{52}$.

Therefore, further studies are necessary to be able to judge its usefulness.

In the articles that hair and nails are considered as biomarkers it has been mentioned that in this material there is the possibility of secondary infection in addition to changes in the hair, such as painting, on the results of curled up why to be affect who used underarm hair.

Wash hair to remove external contamination without hair on content affect the basic and necessary step prior to taking samples of hair and nail magnetic. Magnetic imaging a useful tool for estimating occupational exposure to manganese assessing and measuring the signal strength indicator P. it is widely used because of its easy use.

Two indicators show the status of $\mathrm{P}$ and $\mathrm{T}$, as well as exposure to manganese.

These indicators are useful for monitoring biological monitoring biological exposure with the use of $\mathrm{P}$ index as an indicator of a lack of communication due to the accurate dose - response is limited.

Direct measurement of $\mathrm{T} 1$ is regarded as an option for a person to assess the concentration. Various studies on the impact of manganese on prolactin have reported conflicting results, although many reports have shown that Prolactin manganese in workers exposed to significantly has increased compared with that of the control group $^{68}$. Unlike them, some studies have reported reverse results ${ }^{29,69}$.

This contradiction may be due to nonuniform sampling time or non-uniform distribution of age because age prolactin levels may also be affected.

The highest and lowest concentration of prolactin is during sleep in the waking hours.

In a study by Roels et al. (1992), blood samples from 5.8 to $18 \mathrm{hrs}$ for a day shift and from 20 to 2.5 hrs were collected. Thus, different sampling time can be effective ${ }^{29}$.

\section{REFERENCES}

1. Schulte, P. and J. Hauser, The use of biomarkers in occupational health research, practice, and policy. Toxicology letters, 2012; 213(1): p. 9199.

2. Roels, H., et al., Influence of the route of administration and the chemical form ( $\mathrm{MnCl} 2$, $\mathrm{MnO2}$ ) on the absorption and cerebral distribution of manganese in rats. Archives of toxicology, 1997; 71(4): p. 223-230.

3. Cordova, F.M., et al., Manganese-exposed developing rats display motor deficits and 
striatal oxidative stress that are reversed by Trolox. Archives of toxicology, 2013; 87(7): p. 1231-1244.

4. Santamaria, A., Manganese exposure, essentiality \& toxicity. Indian Journal of Medical Research, 2008. 128(4): p. 484.

5. Gillies, M.E. and J.A. Birkbeck, Tea and coffee as sources of some minerals in the New Zealand diet. The American journal of clinical nutrition, 1983. 38(6): p. 936-942.

6. Greger, J., Dietary standards for manganese: overlap between nutritional and toxicological studies. The Journal of nutrition, 1998. 128(2): p. 368S-371S.

7. Finley, J.W., et al., Dietary manganese intake and type of lipid do not affect clinical or neuropsychological measures in healthy young women. The Journal of nutrition, 2003. 133(9): p. 2849-2856.

8. Saric, M. and M. Piasek, Environmental exposure to manganese and combined exposure to gaseous upper respiratory irritants: mechanism of action and adverse health effects. Reviews on environmental health, 2000. 15(4): p. 413-420.

9. $\quad$ Aschner, M., et al., Manganese: recent advances in understanding its transport and neurotoxicity. Toxicology and applied pharmacology, 2007. 221(2): . 131-147.

10. Murthy, R., et al., Manganese induced testicular changes in monkeys. Experimentelle Pathologie, 1980; 18(4): 240-244.

11. Zheng, W., et al., Biomarkers of manganese intoxication. Neurotoxicology, 2011; 32(1): p. 1-8.

12. Friedman, B., et al., Manganese balance and clinical observations in young men fed a manganese-deficient diet. The Journal of nutrition, 1987; 117(1): p. 133.

13. Dobson, A.W., K.M. Erikson, and M. Aschner, Manganese neurotoxicity. Annals of the New York Academy of Sciences, 2004; 1012(1): p. 115-128.

14. ALI, Y. and B. Abdolhossein, Brain Computer Interface: Principles, Recent Advances and Clinical Challenges. Orient. J. Comp. Sci. \& Technol., 2014; 7(3): p. 425-442.

15. Ali, Y. and S. Hamed, Early Breast Cancer Detection using Mammogram Images: A Review of Image Processing Techniques. Biosci., Biotech. Res. Asia, 2015; 12(Spl.Edn.1): p. 225-234.

16. Yadollahpour, A., Applications of Expert Systems in Management of Chronic Kidney Disease: A Review of Predicting Techniques. Orient. J. Comp. Sci. Technol., 2014; 7(2): p. 306-315.
17. Yadollahpour, A. and M. Jalilifar, Seizure Prediction Methods: A Review of the Current Predicting Techniques. Biomedical \& Pharmacology Journal, 2014; 7(1): p. 153-162.

18. Andersen, M., M. MacNaughton, and H. Clewell, Cincinnati, OH.* Adinolfi M. 1985. The development of the human blood-CSF-brain barrier. Developmental Medicine \& Child Neurology 27: 532-537.* Ahman PK, Dittmer DS. 1974. In: Biological handbooks: Biology data book, Volume III, Bethesda, MD: Federation of American Societies for Experimental Biology, 1987-2008, 2041. Am Ind Hyg Assoc J. 48(4): 335-343.

19. Salehi, F., et al., Bioaccumulation and locomotor effects of manganese phosphate/sulfate mixture in Sprague-Dawley rats following subchronic (90 days) inhalation exposure. Toxicology and applied pharmacology, 2003; 191(3): 264-271.

20. Tapin, D., et al., Bioaccumulation and locomotor effects of manganese sulfate in Sprague-Dawley rats following subchronic (90 days) inhalation exposure. Toxicology and applied pharmacology, 2006; 211(2): 166-174.

21. Zheng, W., et al., Chelation therapy of manganese intoxication with para-aminosalicylic acid (PAS) in Spragueac "Dawley rats. Neurotoxicology, 2009; 30(2): 240-248.

22. Dorman, D.C., et al., Tissue manganese concentrations in young male rhesus monkeys following subchronic manganese sulfate inhalation. Toxicological sciences, 2006; 92(1): 201-210.

23. Eriksson, H., et al., Manganese induced brain lesions inMacaca fascicularis as revealed by positron emission tomography and magnetic resonance imaging. Archives of toxicology, 1992; 66(6): 403-407.

24. Sung, J.H., et al., Changes in blood manganese concentration and MRI t1 relaxation time during 180 days of stainless steel welding-fume exposure in cynomolgus monkeys. Inhalation toxicology, 2007; 19(1): p. 47-55.

25. Lucchini, R., et al., Motor function, olfactory threshold, and hematological indices in manganese-exposed ferroalloy workers. Environmental research, 1997; 73(1): p. 175180.

26. Bast-Pettersen, R., et al., Neuropsychological function in manganese alloy plant workers. International archives of occupational and environmental health, 2004; 77(4): p. 277-287.

27. Blond, M., B. Netterstrom, and P. Laursen, Cognitive function in a cohort of Danish steel workers. Neurotoxicology, 2007; 28(2): p. 328- 
335.

28. Chia, S., et al., Neurobehavioral functions among workers exposed to manganese ore. Scandinavian journal of work, environment \& health, 1993; 264-270.

29. Ellingsen, D.G., et al., A neurobehavioral study of current and former welders exposed to manganese. Neurotoxicology, 2008; 29(1): p. 4859.

30. Lucchini, R., et al., Long-term exposure to” low levels" of manganese oxides and neurofunctional changes in ferroalloy workers. Neurotoxicology, 1998; 20(2-3): p. 287-297.

31. Mergler, D., et al., Nervous system dysfunction among workers with long-term exposure to manganese. Environmental research, 1994; 64(2): p. 151-180.

32. Myers, J.E., et al., The nervous system effects of occupational exposure on workers in a South African manganese smelter. Neurotoxicology, 2003; 24(6): p. 885-894.

33. Roels, H., et al., Assessment of the permissible exposure level to manganese in workers exposed to manganese dioxide dust. British journal of industrial medicine, 1992; 49(1): p. 25-34.

34. Sjögren, B., et al., Effects on the nervous system among welders exposed to aluminium and manganese. Occupational and environmental medicine, 1996; 53(1): p. 32-40.

35. Wang, X., et al., The effect of occupational exposure to metals on the nervous system function in welders. Journal of occupational health, 2006; 48(2): p. 100-106.

36. Yuan, H., et al., A comprehensive study on neurobehavior, neurotransmitters and lymphocyte subsets alteration of Chinese manganese welding workers. Life sciences, 2006; 78(12): 1324-1328.

37. Keen, C.L., et al., Whole-blood manganese as an indicator of body manganese. The New England journal of medicine, 1983; 308(20): 1230-1230.

38. Hoet, P., et al., Manganese in plasma: a promising biomarker of exposure to $\mathrm{Mn}$ in welders. A pilot study. Toxicology letters, 2012; 213(1): p. 6974.

39. Apostoli, P., R. Lucchini, and L. Alessio, Are current biomarkers suitable for the assessment of manganese exposure in individual workers? American journal of industrial medicine, 2000; 37(3): 283-290.

40. Laohaudomchok, W., et al., Toenail, blood and urine as biomarkers of manganese exposure. Journal of occupational and environmental medicine/American College of Occupational and Environmental Medicine, 2011; 53(5): p. 506.

41. Lucchini, R., et al., Neurobehavioral effects of manganese in workers from a ferroalloy plant after temporary cessation of exposure. Scandinavian journal of work, environment \& health, 1995; 143-149.

42. Järvisalo, J., et al., Urinary and blood manganese in occupationally nonexposed populations and in manual metal are welders of mild steel. International archives of occupational and environmental health, 1992; 63(7): p. 495-501.

43. Hua, M.-S. and C.-C. Huang, Chronic occupational exposure to manganese and neurobehavioral function. Journal of clinical and experimental neuropsychology, 1991; 13(4): p. 495-507.

44. Teresa, M., S. Vasconcelos, and H.M. Tavares, Trace element concentrations in blood and hair of young apprentices of a technical-professional school. Science of the total environment, 1997; 205(2): p. 189-199.

45. Hassani, H., et al., Occupational exposure to manganese-containing welding fumes and pulmonary function indices among natural gas transmission pipeline welders. Journal of occupational health, 2012; 54(4): p. 316-322.

46. Wang, D., X. Du, and W. Zheng, Alteration of saliva and serum concentrations of manganese, copper, zinc, cadmium and lead among career welders. Toxicology letters, 2008; 176(1): p. 4047.

47. Gil, F., et al., Biomonitorization of cadmium, chromium, manganese, nickel and lead in whole blood, urine, axillary hair and saliva in an occupationally exposed population. Science of the total environment, 2011; 409(6): p. 11721180.

48. Zhou, Y., et al., [Early biological markers of manganese exposure]. Zhonghua lao dong wei sheng zhi ye bing za zhi= Zhonghua laodong weisheng zhiyebing zazhi= Chinese journal of industrial hygiene and occupational diseases, 2010; 28(9): p. 645-647.

49. Bader, M., et al., Biomonitoring of manganese in blood, urine and axillary hair following lowdose exposure during the manufacture of dry cell batteries. International archives of occupational and environmental health, 1999; 72(8): p. 521-527.

50. Wongwit, W., et al., Comparison of biological specimens for manganese determination among highly exposed welders. Southeast Asian journal of tropical medicine and public health, 2004; 35: 764-769.

51. Jiang, Y., et al., Brain magnetic resonance imaging and manganese concentrations in red blood cells of smelting workers: search for biomarkers of manganese exposure. Neurotoxicology, 2007. 
28(1): 126-135.

52. Cowan, D.M., et al., Manganese exposure among smelting workers: relationship between blood manganeseâ€"iron ratio and early onset neurobehavioral alterations. Neurotoxicology, 2009; 30(6): 1214-1222.

53. Chtourou, Y., T. Boudawara, and N. Zeghal, Protective role of silymarin against manganese induced nephrotoxicity and oxidative stress in rat. Environmental toxicology, 2014; 29(10): p. 1147-1154.

54. Kim, E.A., et al., Effect of manganese exposure on the neuroendocrine system in welders. Neurotoxicology, 2007; 28(2): 263-269.

55. Montes, S., et al., Biomarkers of manganese exposure in a population living close to a mine and mineral processing plant in Mexico. Environmental research, 2008; 106(1): p. 8995.

56. SUN, X., et al., Effect of Occupational Manganese Exposure on Uric Acid Levels in Human Urine. Biomedical and Environmental Sciences, 2011; 24(3): p. 222-227.

57. Schroeder, H.A., J.J. Balassa, and I.H. Tipton, Essential trace metals in man: Manganese: A study in homeostasis. Journal of chronic diseases, 1966; 19(5): p. 545-571.

58. Pejoviæ Miliæ, A., et al., Bone manganese as a biomarker of manganese exposure: a feasibility study. American journal of industrial medicine, 2009; 52(10): p. 742-750.

59. Kim, Y., et al., Motor function in adults of an Ohio community with environmental manganese exposure. NeuroToxicology, 2011; 32(5): 606614.

60. Kim, Y. and B.-K. Lee, Iron deficiency increases blood manganese level in the Korean general population according to Knhanes 2008. Neurotoxicology, 2011; 32(2): p. 247-254.

61. Lucchini, R.G., et al., Neurofunctional dopaminergic impairment in elderly after lifetime exposure to manganese. NeuroToxicology, 2014.

62. Bowler, R.M., et al., Anxiety affecting parkinsonian outcome and motor efficiency in adults of an Ohio community with environmental airborne manganese exposure. International journal of hygiene and environmental health, 2012; 215(3): p. 393-405.

63. Mehra, R. and A.S. Thakur, Relationship between lead, cadmium, zinc, manganese and iron in hair of environmentally exposed subjects. Arabian Journal of Chemistry, 2012.

64. Menezes-Filho, J.A., et al., High levels of hair manganese in children living in the vicinity of a ferro-manganese alloy production plant. Neurotoxicology, 2009; 30(6): p. 1207-1213.

65. de Sousa Viana, G.F., et al., Noninvasive biomarkers of manganese exposure and neuropsychological effects in environmentally exposed adults in Brazil. Toxicology letters, 2014; 231(2): p. 169-178.

66. Montes, S., et al., Serum prolactin rises in Mexican school children exposed to airborne manganese. Environmental research, 2011; 111(8): p. 1302-1308.

67. Choi, D.S., et al., Evaluation of MR signal index for the assessment of occupational manganese exposure of welders by measurement of local proton $<\mathrm{i}>\mathrm{T}</ \mathrm{i}><$ sub $>1</$ sub $>$ relaxation time. Neurotoxicology, 2007; 28(2): 284-289.

68. Yangho, K., High signal intensities on T1weighted MRI as a biomarker of exposure to manganese. Industrial health, 2004; 42: 111-115.

69. Chang, Y., et al., Decreased brain volumes in manganese-exposed welders. Neurotoxicology, 2013; 37: p. 182-189.

70. Chang, Y., et al., High signal intensity on magnetic resonance imaging is a better predictor of neurobehavioral performances than blood manganese in asymptomatic welders. Neurotoxicology, 2009; 30(4): p. 555-563.

71. Long, Z., et al., Vulnerability of welders to manganese exposure-A neuroimaging study. Neurotoxicology, 2014.

72. Ellingsen, D.G., S.M. Hetland, and Y. Thomassen, Manganese air exposure assessment and biological monitoring in the manganese alloy production industry. Journal of Environmental Monitoring, 2003; 5(1): p. 84-90.

73. Myers, J.E., et al., The utility of biological monitoring for manganese in ferroalloy smelter workers in South Africa. Neurotoxicology, 2003; 24(6): 875-883. 